\title{
Nuclear Proliferation and Rules of Retaliation ${ }^{1}$
}

\section{Herman Kahn $\dagger$}

Nearly a decade has passed since any nation has announced an explicit decision to acquire nuclear weapons. Nuclear proliferation has been slow, at least by comparison with many of the pessimistic estimates made in the past, and some analysts expect that its pace will remain as slow in the next decade. Others take a very different view. They point out that the nuclear warheads and carriers are becoming - at least from the technological and economic points of view-ever more widely available, and they argue that, for this reason alone, rapid proliferation is much more likely in the next decade or two than in the past. India and Pakistan, Israel and Egypt, Brazil and Argentina, Sweden, Switzerland, Japan or West Germany, might not have to duplicate the efforts of France or China to acquire comparable nuclear capabilities. More important, it has become increasingly clear that quite rudimentary nuclear capabilities might satisfy the political, psychological and even strategic objectives of numerous potential "Nth" countries; it is not always necessary to overtake the superpowers. In short, as far as narrow military, technical and economic obstacles are concerned, proliferation in the coming decade or two might be unprecedentedly rapid. But focusing on military, technical, and economic issues alone is too narrow a view-precisely because these are not as constraining as many thought. It would appear therefore that the political issues should be upgraded from important to dominant. Political analyses of such issues are, of course, inherently uncertain, at least in the medium and long run. Therefore, we will not be able to forecast reliably the future pace of nuclear proliferation. Yet two decades of slow proliferation do raise the hope that future proliferation may likewise be slow-perhaps even slower.

We should note that certain attitudes on nuclear issues are now widespread which were almost unheard of ten years ago, at least in general discussion. Policies aimed at dealing with nuclear proliferation should

$\dagger$ Director, Hudson Institute. B.S. 1945, U.C.L.A.; M.S. 1948, California Institute of Technology.

[1.] This discussion is adapted from a forthcoming Hudson Institute report being prepared in collaboration with Carl Dibble. The ideas contained herein were first presented in a paper delivered to the Third International Arms Control Symposium, April 1966. Printed with the permission of Messrs. James E. Dougherty and John F. Lehman, Jr. 
take some account of these. For example, ten years ago the strategic posture of the U.S. rested in large part on an ability and determination to initiate the use of nuclear weapons to thwart aggression. While this nuclear threat remains important in many respects, prevailing attitudes toward "first use" of nuclear weapons have changed considerably. The U.S. will probably adopt a virtual "no-first-use" policy-perhaps without making a deliberate decision to do so, and perhaps without even calculating all its results. Or again, while it was once believed that "escalation" would be more or less automatic and catastrophic, in the course of a mere five years we have come to believe that escalntion might be deliberately controlled and perhaps even stopped or reversed. The notion of a U.S.Soviet "spasm war," in which all weapons were fired immediately for maximum destructiveness, has ceased to guide military planning in the U.S. (and, it seems likely, in the Soviet Union, France, and elsewhere-despite much rhetoric to the contrary). A more or less implicit sense of appositeness about the use of nuclear threats and attacks has developed. All of this may eventually force some extensive alterations in deterrent strategy, arms-control thinking, and foreign policy in general; and, in turn, all these changes will affect the incentives of various nations to acquire nuclear weapons.

Even very extensive proliferation does not necessarily make worldwide holocaust inevitable-or even particularly likely. This is true even if twenty to thirty independent states have nuclear weapons of various kinds with various systems of command and control. Imagine, for example, that Che Guevarra had two nuclear missiles available to him at some date in the near future. He has said that if this situation came about, he would be unable to restrain himself from launching the missiles at New York City and Washington. In fact, he would probably be considerably less likely to make such a statement, let alone carry it out, if he actually controlled two missiles. But imagine, hypothetically, that he had no sense of responsibility for the country within which he was operating at the time, and that nothing else restrained him from launching the missiles. The United States would probably retaliate in some dramatic and decisive fashion, and other small countries with nuclear systems would be induced as a result to take a second look at their arrangements for controlling nuclear weapons. Although these events would entail immense suffering and destruction, human life would go on. The general pattern of international relations might even continue much as before, and the United States would recuperate rapidly from the damage that the two missiles had inflicted.

Even widespread proliferation might not increase the likelihood of a 
catastrophic U.S.Soviet thermonuclear war very much, if at all. Doubtless the probability of some nuclear use would increase, but even this might be very limited. In the first place, the kind of incident imagined above is not likely to happen more than once, if ever. And if proliferation continues, the attitudes about "first use," the risks of unsafe techniques, disproportionate response, etc., which now inhibit the United States and the United Kingdom might inhibit all or most of the other nuclear states as well. ${ }^{2}$ All nations with large forces and most nations with small nuclear forces might acquire some capability for measured, controlled and deliberate response. Just as "our military and civilian leaders are unanimous," according to a recent Presidential address, ${ }^{3}$ "in their conviction that our armed might is and always must be so controlled as to permit measured response in whatever crises may confront us," so the leaders of other nations would be likely to discover a similar need for controlled capabilities and flexible strategies. An international system in which there had been widespread proliferation might thus be much less accident-prone and aggression-prone than many people have estimated in the past. While we cannot, of course, make definite or reliable forecasts on these inherently uncertain matters, we can say that there are reasons to believe that although proliferation increases many dangers, it alleviates others. In any case one cannot prove that it would necessarily increase the probability of a very serious catastrophe for the U.S. or for mankind.

The argument can even be made that nuclear wreapons make possible a "fair" solution to the problem of national defense, since one country does not have to buy its security at the expense of its neighbor's; in the past, by contrast, even if a country had obtained security by only a moderate superiority, it could usually hope to use that moderate superiority to overwhelm its opponent without suffering catastrophic losses. Any country with a properly designed nuclear deterrent system can hope (so the argument goes) to be strong enough for deterrence and yet not strong enough to execute a disarming first strike against another nuclear power. Thus one country's strength need not necessarily mean its neighbor's weakness-deterrence, unlike superiority, an be both effective and symmetric. Thus one might conclude with Pierre Gallois, that "the further we advance in the ballistic-nuclear age, the more possible it becomes to outlaw violence, even if the aggressor nation is

[2.] A fairly wide range of nuclear uses and the possible aftereffects of the situations are considered by EDaund $O$. Stillaran, Predicting the International Consequenctes of THE INTROduction of Nuclear Weapons (Hudson Institute Pub. No. HI-62l-RR, Jan. 26, 1966).

[3.] N.Y. Times, Jan. 11, 1965, p. 16. 
stronger and more richly supplied with combat means than the nation it threatens." 4

Yet despite all these arguments, we cannot be confident either that the future pace of proliferation will be slow or that its consequences would not be very serious. ${ }^{5}$ In fact, analysts, scholars, policy makers, and men in the street agree not only that it is crucial to decrease the likelihood of nuclear use by those who possess nuclear weapons but also that the spread of those weapons to other countries is itself a source of danger. While all of these people may be wrong, I share their judgment at least in its less apocalyptic form. I will assume in this paper that the reader shares my concern about the danger of future proliferation and wants to improve even the current situation-perhaps by trying to exploit some of the seemingly "desirable" characteristics of the nuclear trends mentioned above, since there may be much wisdom in some of the developments that have occurred or are now occurring.

While there is a wide consensus on the need to inhibit further nuclear spread or use, there are surpisingly few long-term policy ideas on how to do this. A reasonably complete list might go as follows:

1. Attempt, at least temporarily, to prolong the current situation, hoping meanwhile for desirable marginal or far-reaching changes.

2. If the status quo must change, attempt to make it evolve so slowly that much time will be bought and then hope that this time will allow other developments to occur (these other developments are rarely specified).

3. De-emphasize or ignore all long-range problems and deal with each issue as it comes up in a pragmatic and ad hoc fashion.

4. Accept the fact that proliferation will occur and try to live with this "inevitable" large-scale diffusion of nuclear weapons-again in an ad hoc or pragmatic fashion.

5. Work for universal and comprehensive arms-control systems or world government.

It may well be that this list covers the total range of practical policies and that one need not look for anything else; but this seems most doubtful. I have occasionally argued ${ }^{6}$ that serious changes in the international system seem most likely to be made as a result of an intense crisis or a

[4.] Pierre Gallois, The Balance of Terror: Strategy for the Nuclear Age 118 (1961).

[5.] See Kahn, ON Escalation: Metaphors and Scenarios 97.101 (1965) for a discussion of the pros and cons of nuclear proliferation.

[6.] See, e.g., KAhN, ThingING ABout the Unthinkable 153-58 (1962). 
small or large nuclear war. I have also argued that it should be a major objective of negotiations to lay the groundwork for the constructive exploitation of such crises, or of small or large wars. It seems most unlikely that the world will be sufficiently motivated to work out a safer international system as a result of peaceful negotiations around a conference table. But national plans and international negotiations may lay a basis for action in the conditions of changed power relationships and nuclear attitudes which might be the immediate aftermath of some violent world experience or dramatic crises.

I still believe in the value of such preparations. But some ad hoc and pragmatic but important peaceful changes could be made in the current institutional and international environment. These changes could prove large enough to make important differences and yet remain small enough to be achievable.

I will begin by proposing a set of criteria that any long-range "anti-nuclear" policy should try to meet. A description and discussion of such criteria is in itself an important part of the proposed investigation $^{7}$-possibly more important than a debate on the specific proposals. They could, for example, help clear the air for proposals quite different from the ones suggested but which are-again-either more practical or more far-reaching than many which are currently discussed; in any case they attempt to focus attention on the main issues and long-range nuclear issues in general.

\section{Fifteen Criteria for a Long-Range Anti-Nuclear Policy ${ }^{8}$}

The fifteen criteria listed below are, of course, by no means holy writ, nor are they the only ones that could be listed, but they are at least specific examples of what a policy for the nuclear age should accomplish.

1. It should make nuclear weapons be and seem to be practically almost unusable-either politically or physically.

2. In particular, it should be likely to prevent nuclear intimidation.

3. It should decrease the prestige associated with owning nuclear weapons.

[7.] In addition to the forthcoming report by $C$. Dibble and $H$. Kahn, supra note 1 , a discussion of these criteria will be published carly in 1967 in the California Law Review.

[8.] The term "anti-nuclear" is used deliberately, in recognition that some readers would find it a suitable description of the ideas advanced. The term does make a crude sort of point. And there seems no other acceptable term: something like "nuclear defunctionalization" might be a little more precise, but it seems to be objectionable on stylistic grounds. 
4. It should not require Italy, Japan, India, West Germany, or France to accept an invidiously inferior status or an unnecessarily precarious security position.

5. Yet if nuclear weapons are used, it should limit the damage that is done (it should not rely on deterrence working perfectly).

6. Thus, it should be competent to withstand crises, small and even large conventional wars, and some breaches and violations.

7. It should limit proliferation.

8. It should not be aimed at perpetuating U.S. status, porver, and obligations, though it should be conservative in "using" U.S. prestige, morale, and influence.

9. It should not have been foreclosed or embarrassed by prior commitments of the U.S.

10. It should be responsive to national interests, sentiments, and doctrines, and should be negotiable.

11. It should be thoroughly planned so as to be able to become an object of "sudden diplomacy."

12. It should be presented as a political ("above the melee" of normal diplomatic in-fighting and posturing).

13. It should improve current international standards, but should not require thoroughgoing reform.

14. It should be potentially permanent (not necessarily a transitional arrangement) and yet flexible enough to constitute a hedge against events and opportunities in both negotiation and operation.

15. While not designed as a transitional arrangement, it should allow for major or basic developments and changes.

The most telling objection to this list may be not that it is idiosyncratic but that it is too stringent and therefore impractical. Perhaps no policy can meet all of these criteria satisfactorily, but I believe it important to go as far as one can toward meeting them; and the policy I am about to propose attempts to do so. And even if these criteria are idiosyncratic or impractical, the list is intended to be rounded, nonpartisan, provocative (though not unnecessarily so) and of help to skeptics as well as to believers.

\section{One Basic Proposal}

Can nuclear weapons be made so limited in their usefulness that, by and large, they will have relatively little effect on the conduct of international affairs, even in relatively intense crises; moreover can this be 
done in a manner that improves U.S. security and the international order? An affirmative answer to this question would be a good beginning to meeting the suggested criteria for an anti-nuclear policy. The issue, therefore, is not simply whether nuclear weapons will spread, or increase in number. Rather we should be more concerned with the actual and perceived potential usefulness of these weapons, the prestige attached to their possession, their attributes of legitimacy, danger or terror, the felt necessity of various nations in the world to acquire them, and the special role they play in various national policies and postures in normal and crisis situations.

As a first approach imagine a world system in which each nation agrees and expects that nuclear weapons cannot be used legitimately except, possibly, for strict and proportionate retaliation. Each nuclear nation would have adopted a no-first-use policy and a credible policy of responding in commensurate kind and degree if nuclear weapons were used against it. Non-nuclear nations could have made arrangements to have such proportionate retaliation carried out by others. If these expectations seemed reliable and credible, nations could not credibly threaten to use nuclear weapons.

An objective, which could either supplement and complement such a system or be independent of it, would be to restrict legitimate possession (or further acquisition) of nuclear weapons to international organizations-nuclear defense alliances in Western Europe, East Europe, Asia, Latin America, North America, the North Atlantic, or even supraregional nuclear defense organizations.

A third objective might be to establish nuclear-free zones, particularly in those areas of the world which do not currently seem likely to be the scene of direct nuclear confrontations, e.g., Latin America, Africa, the Middle East, parts of Asia, possibly the rim of Europe outside the Western European Union.

All of these objectives are combined in the following long-term "antinuclear" policy:

1. A return to the law of (nuclear) lex talionis, which would be defined not only by the rule of at least an eye for an eye but also (at least between equals) by the further rule of at most an eye for an eye; or, to put it in current jargon, no escalation including no-first-use. ${ }^{9}$

[9.] As discussed in the forthcoming Hudson Institute report, supra note 1, one might modify this rule to distinguish between interior escalation (first use of nuclear weapons on one's own sovereign territory) which does not justify any nuclear reprisal, and exterior 
2. A European nuclear retaliatory force whose sole purpose is to enforce the lex talionis in Europe. This might take the form of a European Strategic Defense Community based upon Western European Union, or it might take some other form. It might not be a Community, or it might be a Community which did not include the United Kingdom, or France, or West Germany.

3. An Asian Nuclear Defense Organization which would enforce the lex talionis in Asia. Probably this could not or should not take the form of an independent Strategic Defense Community, at least initially. Whatever form it did take, the nuclear defense organization might initially be based upon the United States, Japan, Australia, New Zealand, the Philippines, India, Pakistan, and perhaps Great Britain. It could also exclude some of these states, at least initially, and it would probably be-to some great degree -under the effective and perhaps legal control of the United States or perhaps Japan, India and/or Australia.

4. Nuclear-free zones in Latin America, Africa, Eastern Europe, the Middle East, and elsewhere, developed (with modification) from current proposals.

5. A more or less explicit (and perhaps interim) United States (and Soviet Union?) "talionic" guarantee to various non-nuclear areas, which could vary for different areas, and which could be established in terms of likely, minimum, or maximum responses to nuclear provocations as appropriate to each area. The nature of the guarantee might explicitly include provision for change over time.

6. For the denuclearized zones, a long-term program might simultaneously be developed for a non-aligned multilateral nuclear defense organization to play the same role for denuclearized zones as the European and Asian nuclear forces play for their own areas, thus possibly eventually replacing United States (and Soviet Union?) talionic guarantees.

7. Finally, a universal agency could be developed to replace, sup. plement, complement or absorb the various regional and national forces.

escalation (first use of nuclear weapons on an opponent's territory) which does justify reprisal against the homeland. While there are grave objections to trying to make interior escalation legitimate (it would make possession of nuclear weapons more uscful and therefore more attractive) it may be necessary to accept some such compromise to satisfy some European opinion. 
These arrangements probably seem Utopian. But if completely successful, they would limit nuclear weapons to the U.S., the Soviet Union, one international European organization, one international Asian organization, Ghina, and possibly certain other international organizations. The credibility of the talionic response to a nuclear provocation -and therefore the deterrence of provocation-should be high. Not only should nuclear intimidation be difficult but with time even the mere thought of it might be eliminated from crises as well as day-to-day international relations. Yet, if deterrence failed and weapons were used, the result would not inevitably be Armageddon but (assuming expectations are fulfilled) whatever destruction was entailed in the tit-for-tat response. Then conceivably, there would be a return to some previous or ad hoc status quo. The system could conceivably withstand several failures of deterrence and many other intense crises. Except for participation in the Asian nuclear force, this system would immediately reduce U.S. obligations; eventually it would reduce them very sharply. While the United States would be relegated to a status of first among equals, in the long run this would probably be beneficial.

The lex talionis principle amounts to a return to the nineteenthcentury law of reprisal or the practice of primitive communities-particularly ones in which there are no reliable means for maintaining order. By itself, it is therefore not an obviously Utopian notion. It would also seem to provide a clear improvement over a situation in which "spasm" or other all-out war occurs after the nuclear threshold has been crossed. Its damage-limiting potentialities might be exceedingly valuable, especially if alternative means to limit damage prove to be unavailable or unreliable.

In such a tit-for-tat situation (as in most current peace-keeping situations), one does not usually ask who is right. The objective is to bring the violence to a conclusion- "to stop the fighting as soon as possible" -and to create precedents that prevent recurrence. It should be obvious that it would be very difficult to bring violence between equals to a conclusion as long as there is clearly an open-ended account in which one side has done much more damage than the other. Therefore there almost has to be some sort of "equitable," proportionate retaliation before peace can be restored. This is of course exactly the technique adopted by primitive tribes and for much the same reason-they wish to restrain violence, but they have no police and judicial system with which to do it. Of course, tit-for-tat occasionally results in long-continued blood feuds-in other words, it may generate further violence. But more often than not it brings equilibrium. It is only because, as a 
system, it is more likely to support and restore peace than not that it has been so popular in primitive communities. It may still be far better in supplementing the usual system than anything else that is actually available to the international system today.

In this regard it is worth noting that most intelligent laymen in the U.S. now readily understand such points as the following:10 (1) if a small number of nuclear weapons are exploded in a country like the U.S., the President is more likely to ask questions than to press every button; (2) after his questions are answered and he understands the situation, he is still unlikely to lose all control of himself and launch a suicidal "spasm" response; rather he is likely to ask what is in the national interest of the United States, even if-and perhaps especially becausethe situation is agonizing and emotion-filled; (3) the national interest may require a deliberate, measured, controlled and selective response; (4) such a response could occur as a tit-for-tat or other reciprocal retaliation; (5) as a result, millions of people could be killed and yet the war could come to a close with most of the weapons on every side remaining unfired.

Many analysts see the relatively rigid tit-for-tat procedure as a retrogression from modern strategic thinking; it seems to buck the current trend of emphasizing complete flexibility, control, ad hoc calculation and a certain amount of deliberate uncertainty about the response. My proposal does tend toward fixed response, indeed making it almost deterministic, but in a fashion which is quite different from the old massive retaliation doctrine. Rather than prescribing a simple spasm response I am arguing for a response which is never larger than the situation requires.

Thus, surprisingly enough, lex talionis arrangements would be basically consistent with current U.S. policy and with emerging politicalstrategic doctrine. They would extend, make explicit, and seek to institutionalize more generally the profound disposition toward proportionate response now widely held among American officials. Furthermore, this disposition, which certainly exists in other countries as well, is quite likely to affect the contingency policy of other nuclear powers, whether they realize it ahead of time or not. In other words, these proposals are not "Utopian" in the sense of being based on a

[10.] See KAHN, op. cit. supra note 4, at 185-86 \& $\mathrm{n}$. It is interesting to note that much current fiction as well as scholarly analysis has used proportionate response as being the only plausible response in situations in which the only other apparent alternatives are holocaust or an effectively passive acceptance of an extreme provocation. 
far-fetched principle; their Utopian character, if any, lies in requiring an unlikely degree of success in institutionalizing already well-known, sound, and comparatively desirable principles.

Of course, nuclear powers-particularly small ones-argue that a total spasm response is all that they can afford, and any capability for responding in corresponding degree and kind would dangerously decrease the value of their nuclear arsenal as a deterrent. Yet eventually they will almost surely have to propose plans for the contingency in which deterrence fails. Under their present "spasm" doctrine, they are now faced with the unacceptable choice between surrender and nightmarish calamity. Certainly at the "moment of truth" even small nuclear powers are likely to search desperately for alternatives to surrender or holocaust-and they might feel they need advance contingency plans and even declaratory policies that reflect the realistic situation, in order to limit the maximum damage that might occur and to enhance the credibility of their deterrent.

None of the above is certain, of course. But once concrete situations are envisaged, and sequences of events and calculation are spelled out, it is far from probable that a spasm response to nuclear attack will seem preferable. Rather what has now become layman's common sense might suggest basic principles and clearly reasonable assumptions on which to base long-range policy. The nuclear control arrangements envisaged do not presuppose that all nuclear powers will necessarily act calculatingly, and in a measured and controlled manner. But deliberate, measured and controlled behavior can be made more certain by cultivating the disposition to act that way on a world-wide scale (rather than only in the U.S.) and by institutionalizing the principles that seem to be implied in that disposition.

Any proposal that tries to do this will, of course, have to meet many particular objections and difficulties. The forthcoming Hudson Institute report ${ }^{11}$ considers many of these objections or difficulties. Let us consider here only some of the more salient ones.

\section{Some Basic Assumptions and Concepts}

There are certain objections which could reasonably be made on the level of principle, or basic assumption, before going into any discussion of detailed feasibility. For example, the idea of "an eye for an eye" might be manifestly unjust when it actually means "a city for a city," 
and when the city attacked in retaliation is inhabited by persons with no special responsibility for the initial nuclear attack. Serious ethical and political questions are raised, which depend in part upon empirical, analytical and technical considerations, such as what response is proportionate or whether a talionic doctrine would be more unjust or unstable than alternative doctrines. The injustice and other defects of inflexible tit-for-tat must be compared with the possible infeasibility, risk, or even immorality of counterforce, massive city attacks, and other more or less flexible, ambiguous, or unpredictable doctrines as well as the possible consequences of not retaliating at all or not retaliating in a manner that deters further attack. None of these questions can be answered simply or dogmatically. In any case some allowance might be made for responsible authorities to avoid at least the most rigid kind of "city-for-city" retaliation.

The proposed European nuclear retaliatory force would differ in important ways from the multilateral force that was proposed by the U.S. and from the British proposal for an Atlantic nuclear force. I envisage a truly independent nuclear deterrent for Europe, which, while possessing a credible tit-for-tat response, would not permit any member-nation to launch a spasm retaliatory response. A European nuclear defense organization designed in this way would probably represent an increase, rather than a decrease, in the kinds of independence that European nations most desire. Moreover, distinguishing between talionic and escalatory responses lets us solve the problems of the "trigger" (who can launch nuclear weapons) and the safety catch (who can forbid launching). One over-simplified but illustrative possibility would be for everyone to have his finger on the trigger for talionic responses and his finger on the safety-catch for escalation responses, i.e., any nation could authorize a proper tit-for-tat retaliation or forbid excessive escalation. More complex and practical arrangements are discussed in the forthcoming report.

One assumption underlying this proposal is that Western Europe is a "pluralistic security community"- that within the Western European subsystem war is almost literally "unthinkable" and the threat of physical coercion plays almost no role in relations among the nations within the community (though other kinds of threats are occasionally made). Thus no provisions are necessary for the protection of Western European nations from each other (though, in fact, the force could be adapted to such a purpose, if necessary; but this is not envisioned as an important purpose of the force). It is also assumed that Western Europe needs independent power mainly because it does not want to 
continue to be a protectorate of the United States, and not because it seeks to advance any aggressive designs against Communist or other nations.

The Asian countries do not constitute a pluralistic security community and, at least without the United States, there is not the same primarily bipolar (though also polycentric) international alignment as exists between Western and Eastern (including Soviet) Europe. Therefore an Asian nuclear defense organization would have to be different, perhaps more tentative and flexible, and probably with greater U.S. involvement. There might be a special role for Japan and India. Japan in particular seems likely to develop into the dominant non-Communist power in Asia (and it may become more powerful than China).

As time passes, an Asian force would have to develop according to the special requirements of the Asian area. It might ultimately become a true collective security force whose purpose would be to furnish security against aggression by its orw members as well as by other nations. It is premature to try to specify details, though it may be noted that in contrast to the European situation, the two major non-Communist Asian nations, Japan and India, are not unlikely in the future to desire to fulfill national nuclear aspirations within the framework of a regional force, and this expectation is one of the bases (though not an essential one) on which the proposal is built.

Finally, it should be pointed out that while the proposal may seem to have many bizarre aspects, most of the bizarreness derives from coping with an unprecedented situation in which there has not been as much thought about long-range policies and prospects as there might have been. Thus the discussion in this paper will have achieved one important objective if it simply takes the edge off the bizarreness, i.e., if it makes it easier to discuss the problem and to weigh various alternative policies on their merits, rather than on relatively thoughtless (though often deeply held) emotional reactions.

There is, of course, some reason for a quick emotional rejection of such proposals, since to consider them could create problems. Thus they could arouse ambitions for the acquisition of nuclear weapons in nations which are currently more or less satisfied with the status quo (in particular it may increase West German and Japanese nuclear ambitions). These proposals, if accepted, would bring many nations closer to nuclear weapons than they are today. Even the possibility that they may be realized in some form or other can create problems. For example, the so-called "MLF clause" (i.e., the U.S. insistence that any anti-proliferation treaty allow for the creation of a multi-national force 
which absorbs one of the current nuclear forces) seems to be a major block in the negotiation of the current non-proliferation treaty. The possibility of an Asian nuclear force might create similar or greater difficulties. (But the analogy is not completely relevant. The major objection to the MLF clause comes from the Soviet Union, which is clearly worried about West Germany. Furthermore, West Germany's nuclear ambitions, if any, do not have the approval or support of any of its allies on the Continent. In this respect Japan seems to be in a much different position both vis-à-vis the Soviet Union and its own allies.)

Several important issues remain to be considered. For example, what would happen if the various multilateral or other nuclear forces were dissolved? Or if a nuclear organization allowed too much authority to decision makers who might feel substantially more independent of the "political authorities" than would representatives of a nation-state? There are also many possible Soviet reactions to the proposals, and I have not considered any of the pressures or problems that they might create if the proposal were seriously advanced. And nations in non-nuclear regions might object to their status once they see the real possibility of regional (or even national) deterrents working. Eventually they in turn may wish to have a regional deterrent of their own, or they might seek security in some other international organization. The creation of a European Strategic Defense Community would probably increase pressures toward such a solution. And, as already mentioned, my proposal might increase desire for national acquisition of nuclear status in Italy and West Germany. All of the above points and objections must be conceded, and others as well. Nevertheless it seems clear that there is insufficient thought in the government and in scholarly communities about the possibilities or implications of:

1. The use of lex talionis as a guiding principle.

2. The distinction between interior and exterior escalation or between talionic responses and escalation. (Neither of these distinctions seems to have been considered in relation to the MLF, yet they might make all the difference as to its role and to the "trigger" and "safety-catch" problems.)

3. The need for modifying U.S. guarantees if (or as) the Soviet Union acquires a reliable and large second-strike capability.

4. Coming to grips with a situation of increasing multipolarity in which the United States and the Soviet Union will not dominate international relations anywhere near as much as they still do, and in which guarantees which have any hint of "protectorate" about them will be less acceptable. 
Nuclear Proliferation

5. The need to divorce current nuclear arrangements from the political legacy of World War II. The victors must recognize that they cannot keep the nuclear club an exclusive victor's club.

6. The possibility of various ad hoc regional or other special institutions and practices that lie between the usual meliorative and comprehensive proposals, particularly suggestions that may exploit or deal with the concepts suggested above.

7. The fifteen general criteria for a long-range anti-nuclear policy, listed above. 